\title{
Materials Research Society Forum Will Address National Materials Science and Engineering Issues
}

The Materials Research Society will hold a 11/2-day forum on five materials science and engineering issues facing the nation in the next decade. The event, Forum on the Materials Science and Engineering Study, will be held December 4-5 in Boston during the 1986 MRS Fall Meeting. Five sessions will address the five panel topics pursued by the national Materials Science and Engineering Study, commissioned by the National Research Council at the request of the National Academy of Sciences and the National Academy of Engineering.

The five panel topics are:

Panel 1-Materials Research Opportunities and Needs in MSE

Panel 2-Exploitation of MSE and Technology for National Welfare

Panel 3-International Cooperation and Competition in MSE

Panel 4-Research Resources in MSE

Panel 5-Education in MSE

In response to a request for input to the MSE Study from Study Chairs P. Chaudhari (IBM) and M. Flemings (MIT), the MRS Forum will feature representatives from each of the five panels. The representatives will describe the objectives of their panels and their findings to date. An open discussion and presentations by speakers from within the MRS constituency will follow. Papers by the MRS speakers, plus additional MRS contributions, will be published in Communications on the Materials Science and Engineering Study. This book will be available at the Boston Meeting and subsequently from MRS headquarters at a cost of $\$ 8.00$.

The first session on Panel 1-Materials Research Opportunities and Needs in MSE-will open with remarks by B.R. Appleton, the Forum chairman. In addition to the panel's interim report, to be given by James S. Langer, chairman of MSE Study Panel 1, the following papers will be presented:

"Remarks Concerning the Sense of

Community among Materials

Professionals and Its Relevance to

MS\&E" by E.N. Kaufmann

"Electronic and Photonic Materials-

Directions and Opportunities" by

R.C. Dynes

"Glasses and Other Metastable

Metallic Phases by Solid State

Processing Methods" by W.L.

Johnson

"Materials Modification by Energetic Beams" by $\mathrm{H}$. Wiedersich

"Novel Superconducting and

Magnetic Intermetallic Compounds"

by M.B. Maple
"Fast Ion Conductors from Polymers"

by M.L. Kaplan, R.J. Cava, and E.

Rietman

"Icosahedral Boron-Rich Solids for

Very High Temperature

Semiconductors" by D. Emin

"Synthesis of Metastable Materials by High Dynamic Pressures" by W.J.

Nellis, M.B. Maple, and T.H. Geballe

James C. Williams, vice chairman of MSE Study Panel 2 on Exploration of MSE and Technology for National Welfare, will lead off with that panel's interim report. Papers to be presented at this session include:

"Technology Transfer and the

National Laboratories" by R.L.

Schwoebel and K.C. Olsen

"Development of 'EFG' Crystal

Growth over 20 Years as a Case

Study of Technology Funding and

Technology Transfer in Materials

Science" by F.V. Wald

"Materials Data: Requirements for

the Future" by C.J.M. Northrup, Jr.

and J. Rumble

The third session will include the Panel 3-International Cooperation and Competition-interim report by Lyle H. Schwartz, chairman of that panel. Papers for this session will cover the following issues:

"No Guts, No Glory: The Decline of American Manufacturing and Its Impact on Materials Research" by C.B. Duke

"International Competition: The
Case for Cooperating Industrial Institutes" by R.M. Osgood, Jr. "Advanced Processing of Electronic Materials in the United States and Japan-The NRC State-of-the-Art Review" by J.M. Poate, B.R.

Appleton, S.T. Picraux, and P.H.

Rose

"Materials Research - U.S.

Competitiveness" by J.C.C. Fan

Terry L. Loucks, chairman of MSE Study Panel 4, will open the fourth session with that panel's interim report on Research Resources in MSE. Presentations at this session will include:

"Federal Support for Materials

Research" by L.C. lanniello

"Next-Generation X-Ray

Synchrotron Radiation Facilities" by

A. Bienenstock

"Cost Effectiveness in Materials

Science Computer Simulation: The

Role of Dedicated Local Computers"

by B.W. Dodson

"The Center for Neutron Research:

A Major Facility for Materials

Science" by R.M. Moon, C.D. West,

and M.K. Wilkinson

The Panel 5 interim report on Education in MSE will be presented at the final session by I.M. Bernstein, a representative of MSE Study Panel 5. Chaired by Herbert $H$. Johnson and I.M. Bernstein, this session of the Forum will adjourn after an open discussion of the interim report and Panel 5 issues.

\section{Communications on the Materials Science and Engineering Study}

This book is a compilation of all papers contributed to the Materials Research Society which pertain to the Materials Science and Engineering Study.

Price: $\$ 8.00$

Available at the 1986 MRS Fall Meeting, or order from: 